\title{
EVALUATION OF THE ASSOCIATION BETWEEN PROPER INHALER TECHNIQUE AND ANXIETY IN ASTHMA AND COPD PATIENTS DURING COVID-19 PANDEMIC
}

\author{
Mefkure Durmus ${ }^{1}$, Selim Gök ${ }^{1}$, Ömer Faruk Bahçecioğlu ${ }^{1}$, and Süleyman Savaş \\ Hacıevliyagil ${ }^{2}$ \\ ${ }^{1}$ İnönü University Faculty of Pharmacy \\ ${ }^{2}$ Inonu University School of Medicine
}

April 30, 2021

\begin{abstract}
Objective: Medication nonadherence (MNA) is a main problem in patients with asthma and COPD. Association of anxiety and MNA is confusing and is not clear. Improper inhaler technique is an unintentional component of inhaler MNA. In this study, we aimed to investigate the association between inhaler medication usage skills and general anxiety or coronavirus anxiety scales. Materials and methods: Inhaler usage techniques of 70 asthma and COPD patients were evaluated by three clinical pharmacists. The anxiety scores of the patients were calculated by a pulmonologist according to the Hamilton Anxiety Rating Scale (HAM-A) and Coronavirus Anxiety Scale (CAS). Results: Only $32.9 \%$ of the patients were using their inhalers properly. There were only 10 (\%13.3) patients who had all steps correct. CAS score, age, comorbidity and inhaler type were not found to be associated with proper inhaler technique. Only the HAM-A stage $(\mathrm{p}=0.096)$ and educational status $(\mathrm{p}=0.074)$ approached statistical significance in affecting the proper inhaler technique. A weak correlation was found between age and CAS score ( $\mathrm{r}=-$ $0.278, \mathrm{p}=0.02)$. Coronavirus anxiety rate is higher in asthma patients than in COPD patients $(\mathrm{p}=0.036)$. HAM-A and CAS scores of female patients were higher than men $(\mathrm{p}<0.05)$. There was a moderate correlation between HAM-A score and CAS score $(\mathrm{r}=0.407, \mathrm{p}<0.001)$. The correlation between HAM-A score and inhalation skills score approached statistical significance $(\mathrm{r}=-0.208, \mathrm{p}=0.083)$. Conclusion: Most COPD and asthma patients use their inhalers improperly. More attention should be paid to inhaler use skills training, especially in the low education level group and moderate-severe anxiety group.
\end{abstract}

\section{Hosted file}

Manuscript 22.03.2021.pdf available at https://authorea.com/users/411066/articles/520221evaluation-of-the-association-between-proper-inhaler-technique-and-anxiety-in-asthmaand-copd-patients-during-covid-19-pandemic

\section{Hosted file}

Table 1.pdf available at https://authorea.com/users/411066/articles/520221-evaluationof-the-association-between-proper-inhaler-technique-and-anxiety-in-asthma-and-copdpatients-during-covid-19-pandemic

\section{Hosted file}

Table 2.pdf available at https://authorea.com/users/411066/articles/520221-evaluationof-the-association-between-proper-inhaler-technique-and-anxiety-in-asthma-and-copdpatients-during-covid-19-pandemic 